\title{
Analisa Perubahan Kecepatan Pergeseran Titik Akibat Gempa Menggunakan Data SuGar (Sumatran GPS Array)
}

\author{
Bima Pramudya Khawiendratama $^{1)}$, Ira Mutiara Anjasmara ${ }^{2)}$, dan Meiriska Yusfania ${ }^{3)}$ \\ Jurusan Teknik Geomatika, Fakultas Teknik Sipil dan Perencanaan, Institut Teknologi Sepuluh \\ Nopember (ITS) \\ Jl. Arief Rahman Hakim, Surabaya 60111 Indonesia \\ e-mail:ira@geodesy.its.ac.id ${ }^{2)}$; yusfania_mei@geodesy.its.ac.id ${ }^{3)}$
}

\begin{abstract}
Abstrak - Gempa bumi adalah getaran atau guncangan yang terjadi di permukaan bumi akibat pelepasan energi dari dalam secara tiba-tiba yang menciptakan gelombang seismik. Indonesia merupakan Negara dengan aktivitas tektonik terbesar karena Indonesia merupakan pertemuan 3 lempeng besar yaitu lempeng Indo-Australia, lempeng Eurasia, dan Lempeng Pasifik. Hingga saat ini, lempeng Indo-Australia masih terus bergerak di bawah lempeng Eurasia yang mengakibatkan Pulau Sumatera menjadi salah satu pulau di Indonesia dengan aktivitas tektonik yang cukup tinggi dan rawan bencana. Gempa yang terjadi akan menyebabkan deformasi maupun perubahan kecepatan. Gempa yang akan digunakan sebagai penelitian adalah gempa Kepulauan Batu, 14 Februari 2005 dan gempa Sumatra Selatan 29 September 2009. Perhitungan perubahan kecepatan ini dengan menggunakan data dari jaring GPS SuGar (Sumatran GPS Array) pada stasiun pengamatan ABGS, MSAI, NGNG, PTLO, PSMK, PSKI, TIKU dengan pengolahan data menggunakan software GAMIT. Perubahan kecepatan paling besar ada pada stasiun NGNG sebesar $1.02794 \mathrm{~m} / \mathrm{yr}$ pada gempa Sumatra Selatan 29 September 2009.
\end{abstract}

Kata Kunci-Gempa, GPS, Pergeseran, Perubahan Kecepatan.

\section{PENDAHULUAN}

G EMPA bumi adalah getaran atau guncangan yang terjadi di permukaan bumi akibat pelepasan energi dari dalam secara tiba-tiba yang menciptakan gelombang seismik. Gempa Bumi biasa disebabkan oleh pergerakan kerak Bumi (lempeng Bumi). Gempa bumi terjadi akibat aktivitas yang terjadi dibawah permukaan bumi. Gempa bumi tektonik merupakan gempa yang sering terjadi di Indonesia dan dinilai sebagai gempa yang paling merusak. Gempa ini terjadi akibat pergerakan dari lempeng-lempeng yang menyusun bumi, lempeng tersebut dapat bertumbukan, bergesekan, maupun menindih satu sama lain [1]

Indonesia merupakan Negara dengan aktivitas tektonik terbesar karena Indonesia merupakan pertemuan 3 lempeng besar yaitu lempeng Indo-Australia, lempeng Eurasia, dan Lempeng Pasifik [2]. Hingga saat ini, lempeng Indo-Australia masih terus bersubduksi di bawah lempeng Eurasia yang mengakibatkan Pulau Sumatera menjadi salah satu pulau di Indonesia dengan aktivitas tektonik yang cukup tinggi dan rawan bencana [3]. Salah satu bentuk bencana akibat aktivitas tektonik ini adalah bencana alam seperti gempa bumi, tsunami, dan aktivitas vulkanik gunung api.

Dikarenakan aktivitas tektonik yang tinggi di Indonesia upaya menanggulangi kejadian alam tersebut dibutuhkan studi lebih lanjut tentang geodinamika dan analisa deformasi. Dalam lmu geodesi atau geomatika studi geodinamika dan deformasi tersebut membutuhkan data yang teliti dalam geometri posisi dan data harus secara kontinyu atau periodik. Salah satu metode yang dapat digunakan untuk melakukan studi tersebut adalah metode GNSS [1].

Global Navigation Satellite System atau bisa disebut GNSS merupakan teknologi yang digunakan untuk menentukan posisi atau lokasi (lintang, bujur, dan ketinggian) serta waktu dalam satuan ilmiah di bumi. Dalam pemanfaatannya GNSS dapat menjadi stasiun pengamatan secara kontinyu atau biasa disebut dengan CORS [2].

Continuously Operating Reference Stations (CORS) adalah suatu teknologi berbasis GNSS yang berwujud sebagai suatu jaring kerangka geodetik yang pada setiap titiknya dilengkapi dengan receiver yang mampu menangkap sinyal dari satelitsatelit GNSS yang beroperasi secara kontinyu 24 jam per hari, 7 hari per minggu dengan mengumpulkan, merekam, mengirim data, dan memungkinkan para pengguna memanfaatkan data untuk penentuan posisi, baik secara post-processing maupun real-time [6].

Di Indonesia sudah banyak stasiun-stasiun pengamatan CORS, baik yang dikelola oleh Indonesia maupun dikelola oleh negara lain. Pulau Jawa yang dekat dengan zona subduksi memiliki stasiun pengamatan CORS yaitu InaCORS yang dikelola oleh Badan Informasi Geospasial (BIG). Pulau Sumatra merupakan pulau di Indonesia yang juga memiliki stasiun pengamatan CORS yaitu Sumatran GPS Array (SuGAr) yang merupakan stasiun CORS dibawah Earth Observatory of Sigapore, SuGAr tersebar sepanjang $1300 \mathrm{~km}$ di pantai barat pulau Sumatera. Sumatran GPS Array (SuGAr) ini setiap harinya merekam data GPS dengan akurasi tinggi secara kontinyu dan data SuGAr dapat diakses setelah 3 bulan dan dimanfaatkan untuk studi deformasi.

Pada penelitian ini, data yang digunakan untuk menganalisa perubahan kecepatan pergeseran adalah data dari stasiun pengamatan SuGar, sehingga dari tugas akhir ini nantinya diharapkan bisa diketahui perubahan kecepatan serta arah perubahan kecepatan akibat gempa. 


\section{METODOLOGI PENELITIAN}

\section{A. Lokasi Penelitian}

Lokasi yang digunakan adalah sepanjang pantai selatan Sumatra, Indonesia. Terdapat 2 gempa yang diamati dengan masing-masing gempa mempunyai titik beberapa titik pengamatan GPS. Persebaran titik pengamatan GPS disebar disekitar episentrum gempa.

Tabel 1.

Lokasi Penelitian

\begin{tabular}{cccc}
\hline Gempa & Kedalaman & Bujur & Lintang \\
\hline Kepulauan & & & \\
Batu, 14 & $47.1 \mathrm{~km}$ & $98.729^{\circ} \mathrm{BT}$ & $0.127^{\circ} \mathrm{LS}$ \\
Februari 2005 & & & \\
& & & \\
Sumatra & & & \\
Selatan, 29 & $81.0 \mathrm{~km}$ & $99.867^{\circ} \mathrm{BT}$ & $0.720^{\circ} \mathrm{LS}$ \\
September 2009 & & & \\
\hline \hline
\end{tabular}

\section{B. Peralatan dan Data}

Data yang digunakan dalam penelitian ini adalah

1) Data Observasi GPS

Penelitian ini menggunakan data SuGar dengan periode pengamatan sekitar waktu terjadinya gempa. Data ini bisa diunduh secara bebas melalui server SOPAC. Setelah itu dilakukan pemilihan data stasiun pengamatan yang tidak banyak kekosongan data. Data stasiun pengamatan SuGar yang digunakan antara lain ABGS, MSAI, PTLO, PSMK, NGNG, PSKI, TIKU.

Tabel 2.

Data Stasiun SuGar yang Digunakan

\begin{tabular}{|c|c|c|c|c|}
\hline Gempa & $\begin{array}{c}\text { Stasiu } \\
\mathrm{n}\end{array}$ & Bujur & Lintang & $\begin{array}{c}\text { Jarak } \\
\text { dari } \\
\text { Episente } \\
\mathrm{r}(\mathrm{km}) \\
\end{array}$ \\
\hline \multirow{4}{*}{$\begin{array}{c}\text { Kepulaua } \\
\text { n Batu, } 14 \\
\text { Februari } \\
2005\end{array}$} & ABGS & $99.387^{\circ} \mathrm{BT}$ & $0.221^{\circ} \mathrm{LU}$ & 83.25 \\
\hline & MSAI & $99.089^{\circ} \mathrm{BT}$ & $1.326^{\circ} \mathrm{LS}$ & 136.73 \\
\hline & PSMK & $98.280^{\circ} \mathrm{BT}$ & $0.046^{\circ} \mathrm{LS}$ & 50.39 \\
\hline & PTLO & $97.861^{\circ} \mathrm{BT}$ & $0.078^{\circ} \mathrm{LS}$ & 95.87 \\
\hline \multirow{5}{*}{$\begin{array}{c}\text { Sumatra } \\
\text { Selatan, } \\
29 \\
\text { Septembe } \\
\text { r } 2009\end{array}$} & ABGS & $99.387^{\circ} \mathrm{BT}$ & $0.221^{\circ} \mathrm{LU}$ & 118.09 \\
\hline & MSAI & $99.089^{\circ} \mathrm{BT}$ & $1.326^{\circ} \mathrm{LS}$ & 104.28 \\
\hline & $\begin{array}{c}\text { NGN } \\
\text { G }\end{array}$ & $99.268^{\circ} \mathrm{BT}$ & $1.799^{\circ} \mathrm{LS}$ & 136.64 \\
\hline & PSKI & $100.353^{\circ} \mathrm{BT}$ & $1.125^{\circ} \mathrm{LS}$ & 68.53 \\
\hline & TIKU & $99.944^{\circ} \mathrm{BT}$ & $0.399^{\circ} \mathrm{LS}$ & 37.24 \\
\hline
\end{tabular}

2) Data tambahan berupa data permodelan gelombang pasang surut, atmosfer, dan cuaca.

3) Data orbit satelit IGS SP3 ephemeris file (igsWWWD.sp3).

4) Data navigasi RINEX stasiun brdc (brdcDDD0.YYn).

Dimana:

$\mathrm{W}=$ GPS Day

D $\quad=$ Day of Year
$\mathrm{Y} \quad=$ Tahun pengamatan

Peralatan yang digunakan dalam penelitian ini adalah

1) Perangkat Keras (hardware)

a) Laptop

2) Perangkat Lunak (software)

a) Sistem Operasi Windows dan Ubuntu 14.04

b) Microsoft Office

c) Matlab

d) GAMIT

e) GLOBK

f) GMT

\section{Metode Penelitian}

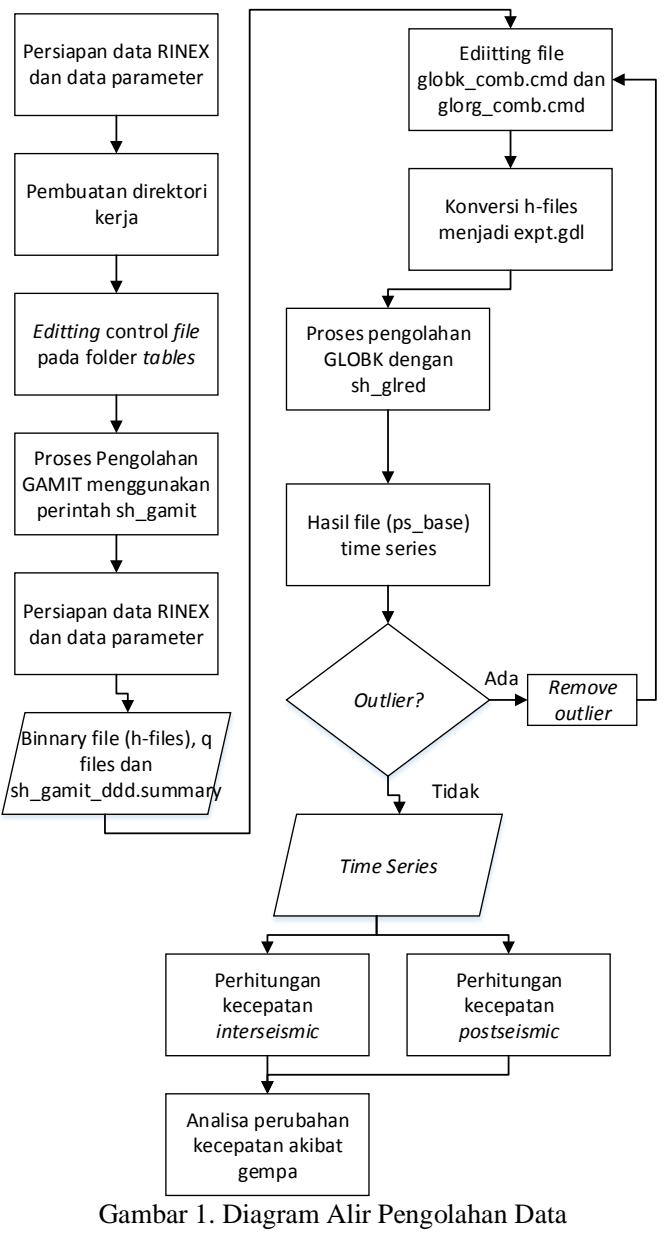

1) Pembuatan direktori kerja

Pembuatan direktori kerja menggunakan perintah sh_setup -yr yyyy -apr <file apr>.apr

Keterangan :

yyyy $=$ tahun data yang akan diolah

file apr $=$ file apr itrf yang akan digunakan

2) Pengolahan GAMIT

Pengolahan data dengan gamit dilakukan dengan pengolahan otomatis dan dengan perintah sh_gamit $-\mathrm{s}$ yyyy DOYa DOYb - expt EXPT -orbit IGSF - eops usno noftp [5].

Keterangan : 
yyyy = tahun data yang akan diolah

DOYa = Day of year pertama dari data yang akan diolah $\mathrm{DOYb}=$ Day of year terakhir dari data yang akan diolah $\mathrm{EXPT}=$ nama project dari data yang diolah

3) Pengolahan GLOBK

Pengolahan GLOBK bertujuan untuk mengkombinasikan hasil pengolahan harian untuk menghasilkan koordinat stasiun rata-rata dari pengamatan yang dilakukan lebih dari satu hari (multidays) dan Melakukan estimasi koordinat stasiun dari pengamatan individual, yang digunakan untuk generalisasi data time series dari pengamatan teliti harian atau tahunan. Perintah untuk menjalankan proses GLOBK dengan menggunakan perintah sh_glred -s YYYYa DOYa YYYYb DOYb - expt EXPT -opt H G E [6].

\section{Keterangan :}

YYYYa = tahun pertama data yang akan diolah

YYYYb = tahun terakhir data yang akan diolah

DOYa $=$ Day of year pertama dari data yang akan diolah $\mathrm{DOYb}=$ Day of year terakhir dari data yang akan diolah EXPT $=$ nama project dari data yang diolah

\section{HASIL DAN ANALISA}

Pada bagian ini akan ditampilkan hasil dari pelaksanaan penelitian yang telah dilakukan.

\section{A. Hasil Plotting Time Series Menggunakan GAMIT/GLOBK}

Menggunakan perangkat lunak GLOBK dapat mendapatkan time series dari data pengamatan GPS. Deret waktu tersebut disesuaikan dengan data pengamatan yang diolah. Untuk gempa Kepulauan Batu menggunakan time series dari day of year 14 sampai 74 di tahun 2005. Sedangkan untuk gempa Sumatra Selatan menggunakan time series dari day of year 241 sampai 302 di tahun 2009.

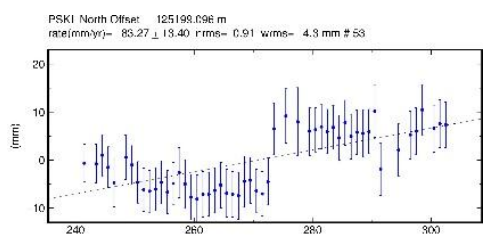

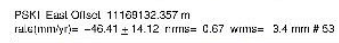

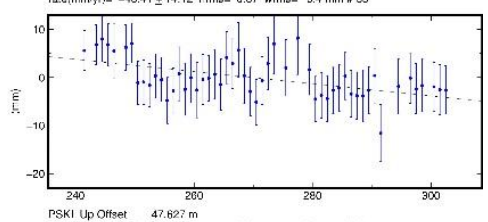

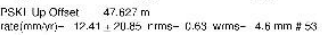

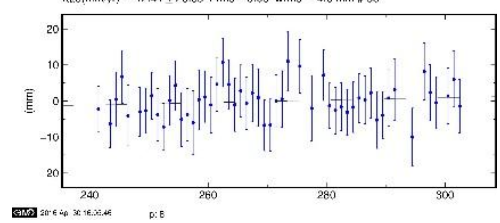

Gambar 2. Contoh Hasil Plotting time series dari Stasiun SuGar

\section{B. Hasil Estimasi Kecepatan Menggunakan Matlab}

Dengan menggunakan perangkat lunak Matlab didapatkan hasil kecepatan tiap stasiun pengamatan GPS.
Tabel 3.

Nilai Kecepatan Pergeseran Stasiun SuGar

\begin{tabular}{cccc}
\hline \hline Gempa & Stasiun & $\begin{array}{c}\text { Kecepatan } \\
\text { Interseismic } \\
(\mathrm{m} / \mathrm{yr})\end{array}$ & $\begin{array}{c}\text { Kecepatan } \\
\text { Postseismic } \\
(\mathrm{m} / \mathrm{yr})\end{array}$ \\
\hline Kepulauan & ABGS & 0.00640 & 0.01760 \\
Batu, 14 & MSAI & 0.00237 & 0.01533 \\
Februari 2005 & PSMK & 0.00759 & 0.00550 \\
PTLO & 0.02097 & 0.00554 \\
Selatan, 29 & ABGS & 0.00425 & 0.02326 \\
September 2009 & MSAI & 0.02023 & 0.00551 \\
& PGNG & 0.00955 & 1.03750 \\
& PSKI & 0.01937 & 0.02727 \\
\hline \hline
\end{tabular}

Pergeseran adalah perpindahan dari posisi awal menuju posisi berikutnya. Sedangkan kecepatan pergeseran adalah besar pergeseran per waktu yang diamati. Nilai kecepatan pergeseran dari tabel 3 didapatkan dari rumus pergeseran $\mathrm{V}_{\mathrm{R}}=\sqrt{\mathrm{Vn}^{2}+\mathrm{Ve}^{2}}$ 


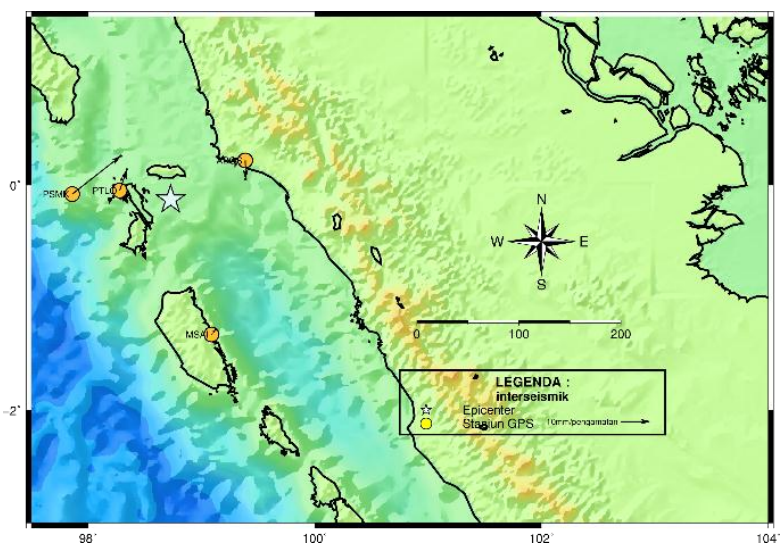

a.

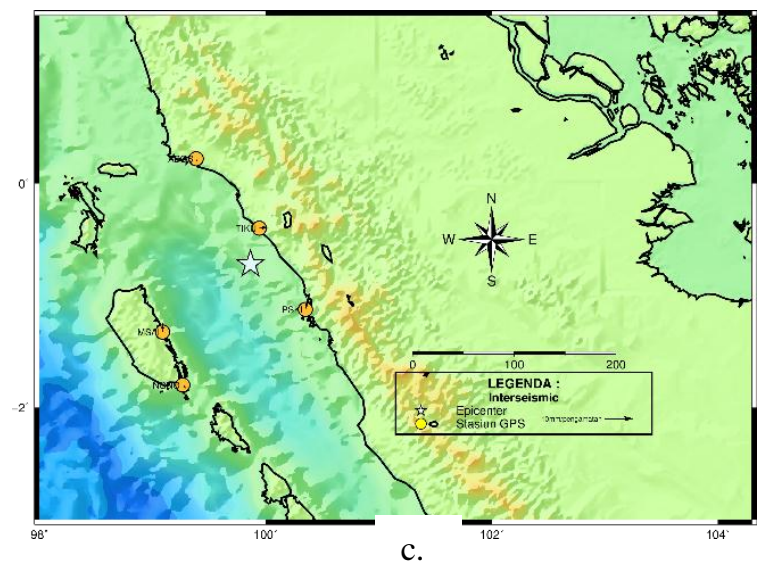

Gambar 3. Visualisasi kecepatan pergeseran (a) interseismic gempa Kepulauan Batu; (b) postseismic gempa Kepulauan Batu; (c) interseismic gempa Sumatra Selatan; (c) postseismic gempa Sumatra Selatan

Tabel 4.

Nilai Kecepatan Pergeseran Stasiun Sugar

\begin{tabular}{ccc}
\hline \hline Gempa & Stasiun & $\begin{array}{c}\text { Selisih Kecepatan } \\
(\mathrm{m} / \mathrm{yr})\end{array}$ \\
\hline & ABGS & -0.01120 \\
Kepulauan & MSAI & -0.01296 \\
Batu, 14 & PSMK & 0.00209 \\
Februari 2005 & PTLO & 0.01543 \\
& ABGS & -0.01901 \\
Sumatra & MSAI & 0.01472 \\
Selatan, 29 & NGNG & -1.02794 \\
September & PSKI & -0.00790 \\
2009 & TIKU & -0.01683 \\
\hline \hline
\end{tabular}

\section{KESIMPULAN}

Adapun beberapa hal yang bisa disimpulkan dari penelitian ini adalah:

1) Nilai kecepatan pergeseran akibat gempa bumi Kepulauan Batu mengakibatkan percepatan pada pergeseran titiknya pada gempa Kepulauan batu ada 2 stasiun pengamatan

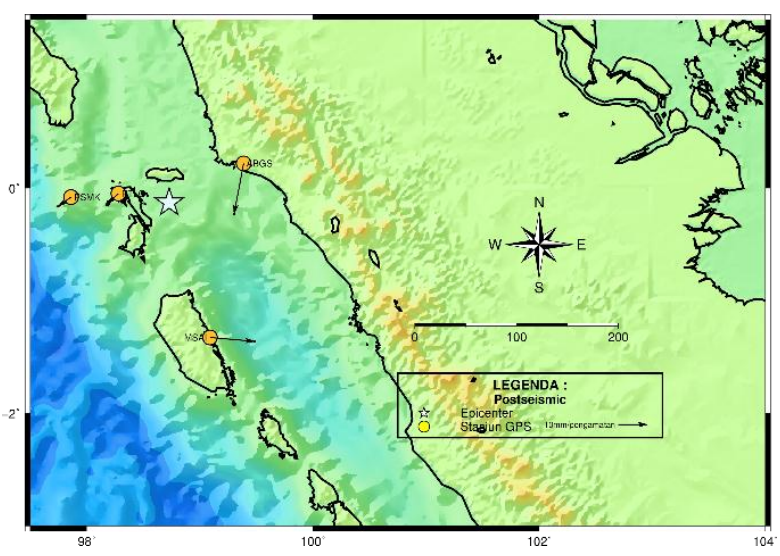

b.

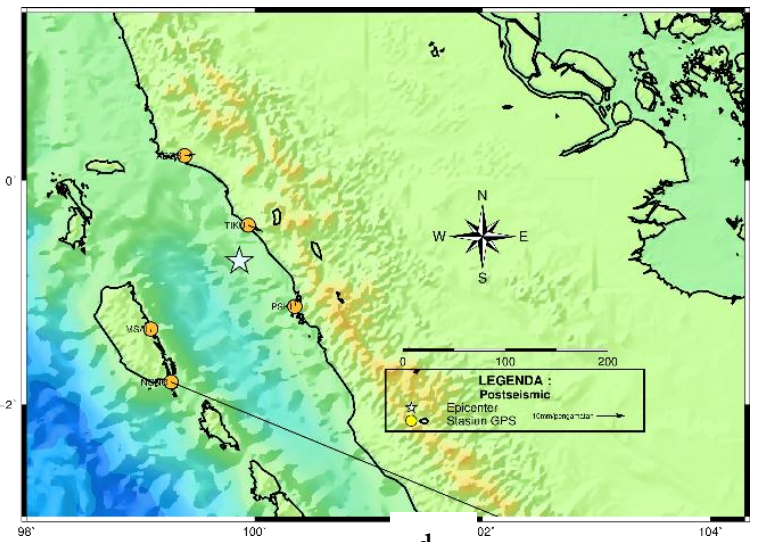

d. yang nilai kecepatannya berkurang yaitu stasiun ABGS dan MSAI yaitu sebesar $-0.01120 \mathrm{~m} / \mathrm{yr}$ dan $-0.01296 \mathrm{~m} / \mathrm{yr}$ dan pada gempa Sumatra Selatan semua titik kecepatanya berkurang kecuali MSAI memiliki nilai pergseran 0.01472 $\mathrm{m} / \mathrm{yr}$.

2) Nilai perubahan kecepatan pergeseran pada gempa Kepulauan Batu, 14 Februari 2005 paling besar terjadi pada stasiun PSMK dengan perubahan kecepatan sebesar $0.00209 \mathrm{~m} / \mathrm{yr}$ dan perubahan kecepatan paling kecil ada pada stasiun PTLO dengan besar pergeseran $0.01120 \mathrm{~m} / \mathrm{yr}$.

3) Nilai perubahan kecepatan pergeseran pada gempa Sumatra Selatan, 29 September 2009 paling besar terjadi pada stasiun NGNG dengan perubahan kecepatan sebesar $1.02794 \mathrm{~m} / \mathrm{yr}$ dan perubahan kecepatan paling kecil ada pada stasiun PSKI dengan besar pergeseran $0.00790 \mathrm{~m} / \mathrm{yr}$. 


\section{DAFTAR PUSTAKA}

[1] H. Andreas, Karakteristik Deformasi Strain dan Stress, Bandung: Prodi Geodesi dan Geomatika ITB, 2007.

[2] BMKG, "Tentang," 2015. [Online]. Available: http://inatews.bmkg.go.id/news/tentang_eq.php. [Accessed 22 Desember 2015].

[3] J. McCaughet, Sumatran Earthquakes with GPS, Singapore: Earth Observatory of Singapore, 2012.

[4] H. Abidin, "Deformasi Koeseismik dan Pascaseismik Gempa Yogyakarta 2006 dari Hasil Survei GPS," Jurnal Geologi Indonesia, vol. IV, no. 4, Desember 2009.

[5] H. Z. Abidin, Penentuan Posisi dengan GPS dan Aplikasinya, Jakarta: PT PRADNYA PARAMITA, 2006
[6] T. P. Ramadhan, Analisis Deformasi Pulau Bali Berdasarkan Pengamatan GPS Kontinu Tahun 2010-2012 dan GPS Berkala Tahun 2013, Bandung: Institut Teknologi Bandung, 2014.

[7] T. A. Herring, GAMIT Reference Manual GPS Analysis at MIT, San Diego: Departement of Earth, Atmospheric ang Planetary Sciences Massachusetts Institute of Technology, 2015.

[8] T. A. Herring, GLOBK Reference Manual: Global Kalman Filter VLBI and GPS Analysis program, San Giego: Departement of Earth, Atmospheric ang Planetary Sciences Massachusetts Institute of Technology, 2015. 